\title{
O CURSO DE MAGISTÉRIO RURAL E A ORGANIZAÇÃO CURRICULAR NA FORMAÇÃO DO PROFESSOR LEIGO PRIMÁRIO NO MUNICÍPIO DE DOURADOS-MT (DÉCADA DE 70 DO SÉCULO XX)
}

\author{
The Rural Magisterium course and the formation of the primary lay teacher in the \\ municipality of Dourados-MT (70's of the twentieth century)
}

\section{El Curso de Magisterio Rural y la formación del profesor laico primario en el municipio de Dourados-MT (década del 70 del siglo XX)}

Ana Paula Fernandes da Silva Piacentine*

Alessandra Cristina Furtado**

\begin{abstract}
Resumo
Este artigo tem por objetivo analisar a implantação e o funcionamento do curso de Magistério Rural, instalado no município de Dourados, na década de 1970. Esse recorte justifica-se por sinalizar o período de criação e vigência do curso. Recorre-se a um referencial teórico voltado para a História, Memória, História da Educação, entre outros. Para desenvolver este trabalho, foram utilizados documentos preservados em Arquivos, Museus e Centros de Documentação e entrevistas com professores e alunos. Esse curso configurou-se com uma cultura escolar específica, que permite compreender as particularidades e as experiências realizadas na formação de professores leigos rurais primários do município de Dourados, no sul de Mato Grosso, na década de 1970.
\end{abstract}

PALAVRAS-CHAVE: História da educação. Magistério Rural. Ensino primário. Formação de professores primários rurais.

\begin{abstract}
This paper aims to examine the implementation and performance of a Rural Teacher Training Program put into practice in the town of Dourados, in the 1970s. This time period is justified because the implementation and duration of the course occurred throughout the 1970s. A theoretical framework focused on History, Memory, History of Education, among others is used. Information on historical records available at Documentation Centers, Archives and Museums allowed for the development of this study. Moreover, some interviews with teachers and students were conducted. Specific cultural characteristics in schools have shaped educational structure, therefore allowing one to better understand the pedagogical theories and practices that were applied to the formation of lay rural primary teachers in the town of Dourados, in the south Mato Grosso, in the 1970 decade.
\end{abstract}

\footnotetext{
*Professora Tutora do Centro Universitário da Grande Dourados (UNIGRAN). Professora do Ensino Fundamental I da Escola Presbiteriana Erasmo Braga de Dourados. Mestre em Educação pela Universidade Federal da Grande Dourados. E-mail: anaapaulapiacentine@ hotmail.com

** Professora da graduação e da pós-graduação (Mestrado e Doutorado em Educação) da Faculdade de Educação da Universidade Federal da Grande Dourados (UFGD). Doutora em Educação pela Universidade de São Paulo (USP). Pós-doutora em Educação pela Universidade de São Paulo (USP). E-mail: alessandra_furtad@yahoo.com
} 
KEYWORDS: History of Education. Rural Education. Primary education. Formation of primary school teachers in rural areas.

\section{Resumen}

Este artículo tiene por objetivo analizar la implantación y el funcionamiento del Curso de Magisterio Rural, instalado en el municipio de Dourados, en la década de 1970. El recorte en la década de 1970 se justifica por señalar el período de creación y vigencia del curso. Se recurre a un referencial teórico orientado hacia la Historia, Memoria, Historia de la Educación, entre otros. Para desarrollar este trabajo, se utilizaron documentos preservados en Archivos, Museos y Centros de Documentación y entrevistas con profesores y alumnos. Este curso se configuró con una cultura escolar específica, que permite comprender las particularidades y las experiencias que se realizaron en la formación de profesores laicos rurales primarios del municipio de Dourados, en el sur de Mato Grosso, en la década de 1970.

PALABRAS CLAVE: Historia de la Educación. Magisterio Rural. Enseñanza primaria. Formación de profesores primarios rurales.

\section{INTRODUÇÃO}

Iniciativas para a habilitação de professores leigos ${ }^{1}$ rurais primários registram-se, desde os anos de 1930, no Brasil, com a primeira Escola Normal Rural criada em Juazeiro do Norte (Ceará), em 1934. Essa instituição de formação de professores surgiu com o movimento de ruralização do ensino primário (1930), que tinha o objetivo de criar cursos especiais normais para professores leigos rurais, nos moldes preceituados pela ideia de "adaptação curricular" (WEREBE, 1963).

A análise efetuada no artigo incide sobre o Curso de Magistério Rural que funcionou na década de 1970, no município de Dourados, no sul de Mato Grosso. O recorte temporal justifica-se pelo fato de os anos de 1970 sinalizaram como o período de criação e vigência desse curso.

Bastos (2010), ao prefaciar o livro "Educação Rural: práticas civilizatórias e institucionalização da formação de professores", de organização de Flávia Obino Corrêa Werle (2010, p.07) registra que os estudos sobre “ [...] a educação rural e a formação de professores - permite preencher uma lacuna da história da historiografia da história da educação na América Latina e, especialmente, no Brasil". Já para Ávila (2013) em sua tese de doutorado intitulada " História do ensino primário rural em São Paulo e Santa Catariana (1921-1952)" defendida na Universidade Estadual Paulista, Campus de Araraquara realizou um levantamento da produção acadêmica sobre a abordagem histórica da educação rural no Brasil e acabou por apresentar a partir deste levantamento, que apesar de ter localizado investigações específicas sobre o tema educação rural, pesquisas sobre essa temática ainda permanece na "[...] lacuna de estudos historiográficos relativos ao contexto em que se

\footnotetext{
${ }^{1} \mathrm{O}$ "professor leigo" é o profissional que exerce o magistério sem possuir habilitação mínima exigida. Segundo o Thesaurus do Instituto Nacional de Estudos Pedagógicos - INEP, do Ministério de Educação - MEC, trata-se da pessoa que trabalha como docente, sem ter terminado o curso necessário que lhe permita obter o título correspondente ao nível de ensino em que leciona. São pessoas que lecionam sem ter concluído o curso que as habilitam ao exercício do magistério no nível de ensino em que atuam (AUGUSTO, 2018, p. 1).
} 
desenvolveram as políticas educacionais e a introdução de modelos educativos para o ensino primário rural no transcorrer do século 20 no Brasil" (ÁVILA, 2013, p. 22). Em artigo recente intitulado "Educação Rural em Perspectiva Histórica", Ávila (2018, p. 02) registrou que esse quadro da produção historiográfica sobre a educação rural no Brasil, “[...] apresentou uma sensível mudança entre os anos de 2010 e 2016, quando se observa um interesse maior por um campo de pesquisa ainda pouco explorado".

No caso de Mato Grosso e Mato Grosso do Sul, a produção acadêmica em torno da educação rural em uma perspectiva histórica iniciou e intensificou há menos de uma década. Das dissertações já produzidas até o momento, temos os trabalhos de autores como: Silva (2018b), Castro (2018), Ebenritter (2018), Cavalcante (2016), Beck (2015), Irala (2014), Piacentine (2012), Silva (2012). Já em relação as teses temos os estudos de Paes (2011) e Silva (2018a). Esses trabalhos permitem constatar que essa produção acadêmica se encontra mais circunscrita em torno de dissertações de mestrado do que de teses de doutorado e, que além disso, os objetos de estudos abordados nessa produção também possibilitam verificar que se direciona mais para pesquisas sobre a história, memória e cultura escolar das escolas primárias rurais.

Devido a produção acadêmica sobre a Educação Rural numa perspectiva histórica em Mato Grosso e Mato Grosso do Sul, constituir-se em um campo de pesquisas em construção e aberto a novos estudos, que o presente artigo emerge com o objetivo de analisar a implantação e o funcionamento do curso de Magistério Rural, instalado no município de Dourados, na década de 1970, e se insere nas pesquisas e publicações sobre a história e a historiografia da Educação Rural no Brasil, e mais especificamente, nas investigações acerca da história da formação dos professores de escolas primárias rurais. Este artigo é um dos resultados de uma pesquisa de mestrado que se dedicou a investigar o Curso de Magistério Rural que funcionou na década de 1970, no município de Dourados.

Na busca por analisar a implantação e o funcionamento do Curso de Magistério Rural, instalado no município de Dourados, na década de 1970, recorremos as fontes documentais e orais, como os documentos preservados nos Centros de Documentação, Arquivos Públicos e Museus de Mato Grosso e Mato Grosso do Sul, e entrevistas com ex-alunas e antiga professora do curso. Nos acervos citados acima, foi possível levantar as Mensagens de Governadores do Estado de Mato Grosso, Ofícios, Dados da Secretaria de Planejamento do Governo de Mato Grosso de 1973, Noticiários de Jornais do período pesquisado, entre outros.

Embora não tenha sido fácil localizar ex-alunos e antigos professores do Curso de Magistério Rural do município de Dourados, foi possível selecionar partir de documentos localizados e de uma busca minuciosa, três ex-alunas e uma antiga professora do Curso para entrevistar. Essas três ex-alunas ainda são moradoras do município de Dourados e a antiga professora, atualmente, reside na capital de Mato Grosso do Sul, na cidade de Campo Grande. As entrevistas foram realizadas por meio de um roteiro de questões semiestruturadas e mediante a técnica do gravador, pois "essa técnica permite acompanhar com fidelidade os monólogos dos informantes, ou o diálogo entre o informante e o pesquisador, para guardá-los ou interpretá-los posteriormente" (QUEIROZ, 1991, p.56). Cada uma das depoentes assinou um Termo de Consentimento Livre e Esclarecido concendo o direito de uso dos dados nessa pesquisa.

Entretanto, as entrevistas não foram tomadas como reveladoras da verdade. Neste aspecto, vale lembrar como aponta Alberti (2005, p. 67), “[...] que a memória é resultado de um trabalho de organização e de seleção do que é importante para o sentimento de unidade, de continuidade e de coerência - isto é identidade". O caráter seletivo da memória faz lembrar acontecimentos que, por alguma razão, foram significativos e, ao serem rememorados, 
apresentam aspectos sobre a existência individual contida em determinados períodos históricos.

Diante disso, procuramos realizar a investigação com base na documentação encontrada nos Centro de Documentação, Arquivos Públicos e Museus de Mato Grosso e Mato Grosso do Sul e nas entrevistas de professores e alunos do curso, bem como em uma bibliografia relativa à história de Mato Grosso, à história e historiografia da educação, à história da formação de professores, à memória, entre outras.

Este artigo foi organizado em quatro partes que se complementam. A primeira versa sobre o percurso histórico da história da formação de professores no Sul de Mato Grosso. A segunda parte aborda a história da formação de professores no município de Dourados. A terceira trata da implantação e do funcionamento do Curso de Magistério Rural no município de Dourados. E, por fim, a quarta parte discute a organização curricular do Curso de Magistério Rural pelo relatos das ex-alunas e antiga professora.

\section{Itinerário histórico da formação do professor primário no Sul de Mato Grosso: alguns apontamentos}

No Sul de Mato Grosso, embora o município de Campo Grande, desde o final dos anos de 1920, estivesse passando por transformações no que se refere à urbanização e à modernização da economia e dos meios de comunicação, a educação escolar era ainda esquecida, tanto que o primeiro grupo escolar foi instalado somente em 13 de junho de 1922, criado pela Resolução $\mathrm{n}^{\text {0. }} 846$, de 03 de novembro de 1921. Esse grupo foi

\footnotetext{
O sétimo de uma lista de onze estabelecimentos criados em Mato Grosso no período de 1910-1927, a partir das reformas da instrução pública empreendidas na primeira gestão de Pedro Celestino Corrêa da Costa [...] (OLIVEIRA; RODRÍGUEZ, 2009, p.106).
}

Pouco tempo depois, anexo ao Grupo Escolar, foi instalada, em 21 de abril de 1930, a Escola Normal de Campo Grande, pelo então presidente de Estado, Dr. Aníbal Toledo, tornando-se a primeira instituição sul-mato-grossense dessa natureza e a segunda do estado. Pode-se dizer que tal fato permite confirmar o atraso do desenvolvimento do sul do Estado em relação ao norte, visto que este só teve a instalação da Escola Normal 20 anos após a instalação da primeira Escola Normal, em Cuiabá.

Embora não bastasse essa espera, Campo Grande se deparou com o fechamento dessa instituição, dez anos após sua instalação. Em 1940, a Escola Normal foi fechada em consequência da reforma que o governo de Júlio Strübing Müler (1937-1945) tentou implantar. Após a referida reforma, a escola permaneceu fechada por um período de sete anos, período esse em que o estado contava com três ginásios oficiais nas cidades de Cuiabá, Corumbá e Campo Grande, instituições destinadas à formação de professores. Para tanto, funcionava junto aos liceus uma Seção Normal, que era a antiga Escola Normal, e o curso especializado de professores.

Foi somente no governo de José Marcelo Moreira (1946-1947) que a Escola Normal de Campo Grande foi restituída oficialmente, por meio do Decreto-Lei $n^{\text {o. }} 834$, de 31 de janeiro de 1947, que a organizou em dois ciclos, de acordo com as prescrições estabelecidas pela Lei Orgânica do Ensino Normal de 1946: 
Art.1- Fica o Poder Executivo autorizado a criar, nos termos do decreto-lei n. 8530, de 2 de janeiro de 1946, duas Escolas Normais na Capital do Estado e em Campo Grande, com as designações respectivamente de, Escolas Normal "PEDRO CELESTINO" e "JOAQUIM MURTINHO".

Art. 2 -, que serão dirigidas respectivamente por diretor padrão M, em comissão e diretamente subordinado ao Departamento de Educação e Cultura do Estado, destinam-se a prover a formação do pessoal docente necessário ás escolas primárias do Estado.

Art. 3 - As Escolas Normais "PEDRO CELESTINO" e "JOAQUIM MURTINHO" de conformidade, com a Lei Orgânica do Ensino Normal no país, ministrarão o ensino em dois ciclos. O primeiro dará o curso de regentes do ensino primário, em quatro (4) anos, e o segundo o curso de formação de professores primários, em três (3) anos. (MATO GROSSO, Decreto, 1947).

Ainda no governo de José Marcelo Moreira foi elaborado o Regulamento das Escolas Normais do estado, promulgado pelo Decreto $n^{\text {o. }}$ 287, de 26 de março de 1947, que determinava:

Art. 1 - o ensino normal tem por fim:

- Promover a formação do pessoal necessário ás Escolas primárias do Estado.

- Habilitar administradores escolares destinados às mesmas escolas.

- Desenvolver e propagar os conhecimentos e técnicas relativas à educação da infância.

Art. 2 - O ensino ministrado pelas Escolas Normais do Estado será gratuito e facultado a ambos os sexos.

Durante o governo de José Marcelo Moreira (1946-1947), o Ensino Normal em Mato Grosso conheceu um processo de reabilitação e propagação. Marcílio (1963) ressalta que a partir desse processo se implantaram ações políticas, concedendo ao setor privado o Ensino Normal e delegando a formação de professores, principalmente, ao setor confessional. Também foram instaladas, nesse mesmo período, no sul de Mato Grosso, a Escola Normal anexa ao Ginásio Maria Auxiliadora, pertencente à Congregação das Filhas de Maria Auxiliadora, ala feminina da Ordem Salesiana, em Campo Grande, e outra Escola Normal privada, também mantida pelas Irmãs Salesianas, em Corumbá. Em 1949, por meio da Lei nº. 342, foi criada no sul do estado a Escola Normal de Aquidauana.

Apesar desse processo de reabilitação e propagação do Ensino Normal desencadeado pelo governador José Marcelo Moreira, a Escola Normal de Campo Grande, a segunda instituição oficial do Estado de Mato Grosso, ainda permaneceu funcionando em condições precárias até o final da década de 1960 e início de 1970.

No governo de Fernando Corrêa da Costa, entre 1951 e 1956, em mensagem de 1952, o governador reconhece as dificuldades que o estado de Mato Grosso enfrentava em relação às condições do ensino. Para ele, um dos problemas que refletiam na educação estava relacionado às dimensões geográficas do estado, principalmente devido à concentração da população na zona rural em idade escolar. Outro problema que também dificultava a educação era a falta de professores habilitados. Segundo o governador Fernando Corrêa da Costa,

(...) Distribuir escolas numa imensa, entre população de densidade tão apoucada, é o empreendimento mais penoso que ao Departamento de Educação e Cultura, o órgão responsável por esse importante setor de administração, cumpre realizar. E quando atentamos que à escola cabe a função de instruir e de educar, isto é, preparar na 
infância homens aptos para a vida, equaciona-se, então, o seu problema culminante que é o do professor a quem cabe a execução dessa magna tarefa.

Porque ensinar, mesmo que sejam noções apenas dos programas de ensino, implica ter conhecimento que não se cifram somente à leitura, à escrita e à contabilidade, mas de higiene, saúde, domínio da terra dos assuntos sociais mais de interesse da coletividade em que atua o professor, a quem também não se dispensou o senso psicológico. Recrutar elementos portadores desses predicados, numa terra onde as aptidões são chamas a atividades mais atraentes quer sob o aspecto da labuta, quer sob o prisma econômico, é o cruciante trabalho quer se depara à administração (MATO GROSSO, Mensagem, 1952).

Outras dificuldades mencionadas se relacionavam à contratação de professores do sexo masculino e à falta de professores diplomados. Para Fernando Corrêa da Costa, essa situação afetava, principalmente, a educação rural.

Cumpre observar que, por força desses pressupostos, as Escolas Normais
apresentam frequência mínima em relação a outros estabelecimentos. O elemento
masculino, aqui no Estado, desertou completamente dessa disciplina.
Somos forçados a reconhecer que o ensino em Mato Grosso está sofrendo uma
perigosa involução, um ressaltante retrocesso. É verdade que para as escolas das
cidades especialmente das que oferecem melhores condições de conforto e de
progresso, ainda se obtém professora, o que não se registra quando se trata de
preenchimento das unidades rurais. Diante dessa contingência, as mais das vezes,
vemos guindados à posição de professor criaturas semi-analfabetas (MATO
GROSSO, Mensagem, 1952)

Embora a formação de professores das áreas rurais fosse um problema enfrentado por todo o sul do Estado, essa questão era bastante agravante. É importante assinalar que a implantação de políticas para habilitação dos professores leigos, nos anos de 1960, em nível pedagógico, por meio de metodologia de ensino direto, no período de férias, e indireto, oferecido em período letivo, fez-se presente com a criação e o trabalho desenvolvido pelo Centro de Treinamento do Magistério de Cuiabá.

O Centro de Treinamento do Magistério de Cuiabá foi criado no contexto da Reforma do Ensino Primário promovida pelo Governo João Goulart, no período de 1963 a 1964. O Plano Trienal de Educação de João Goulart ${ }^{2}$ tinha como projeto instituir nada menos que 40 Centros de Treinamento do Magistério nos próximos 8 anos e, talvez, para os próximos 3 anos, pelo menos 18 destes centros em diferentes localidades do Brasil (FERREIRA, 2010). No caso de Mato Grosso, a instalação do Centro de Treinamento do Magistério de Cuiabá fezse em um período de extrema necessidade e urgência para o Estado. A esse respeito, o exsecretário estadual de Educação e Saúde do Mato Grosso, Humberto Marcílio, anunciava que "[...] em 1963, mais de 60\% dos professores primários que atuavam no Estado não tinham formação adequada" (MARCÍLIO, 1963, p. 214).

No Centro de Treinamento do Magistério de Cuiabá eram oferecidos cursos de especialização em supervisão escolar para professoras normalistas e cursos de

\footnotetext{
${ }^{2}$ O Plano Trienal de Educação de João Goulart, “além de estabelecer objetivos para o ensino primário, médio e superior, previa os recursos financeiros e a assistência técnica necessários à implantação de programas de construções de prédios escolares e de recuperação e aperfeiçoamento do magistério" (BRASIL, 1963 apud. FERREIRA, 2010, p.149). Nesse contexto, o Programa de Aperfeiçoamento do Magistério Primário (PAMP) foi criado em 1963, pelo governo federal, com o objetivo de subsidiar os cursos já mencionados, voltados para a habilitação de professores leigos. A partir deste Programa, os recursos se multiplicaram (RODRIGUES, 1985).
} 
aperfeiçoamento para professoras qualificadas como "leigas" (FERREIRA, 2010). A autora, ainda, ressalta:

\begin{abstract}
Nesses cursos, oferecidos para professoras de diversas partes do Estado, a ênfase recaía sobre a introdução de novas técnicas e métodos de ensino, além de procedimentos de planejamento educacional e supervisão escolar, considerados inovadores à época (FERREIRA, 2010, p.146).
\end{abstract}

No início de seu funcionamento, o centro deparou-se com a dificuldade de contratação de pessoal habilitado. No entanto, para resolver essa situação, foram convocados docentes para realizar cursos de "especialização em matérias do currículo primário e de especialização em supervisão, oferecidos pelo Centro de Treinamento de Belo Horizonte, que funcionava junto ao PABAEE ${ }^{3}$ (Programa de Assistência Brasileiro-Americana ao Ensino Elementar)" (PINHO, 1964, p. 6).

Mesmo com a saída de João Goulart, em virtude do Golpe Militar de 1964, o Centro de Treinamento do Magistério manteve o seu funcionamento, respeitando as determinações dos dispositivos relativos à educação, presentes no Programa de Ação Econômica do Governo (PAEG), elaborado sob a coordenação do economista Roberto Campos. Porém, a partir deste período de 1964, o Centro de Treinamento do Magistério de Cuiabá passou a concentrar-se mais nas atividades de oferta de cursos de férias a professoras "leigas" e cursos de difusão de novos métodos pedagógicos. Os cursos de férias eram cursos intensivos de aperfeiçoamento do professorado leigo, realizados em Cuiabá. Já os cursos de difusão de novos métodos pedagógicos, com duração de 15 dias, eram oferecidos por uma equipe de professoras especialistas, para professoras de Escolas Normais, Ginásios e Escolas Primárias públicas e privadas, em seus municípios de origem (FERREIRA, 2010).

É nesse quadro constituído tanto pelas poucas escolas normais quanto pela atuação do Centro de Treinamento de Cuiabá que ocorria a formação dos professores primários no sul de Mato Grosso, ainda no início dos anos de 1970. No que diz respeito à Escola Normal de Campo Grande, uma perspectiva de mudança só se tornou possível em 1973, quando finalmente foi determinada a integração do Grupo Escolar "Joaquim Murtinho" à Escola Normal no município de Campo Grande, pelo Decreto Estadual $n^{\text {o. }} 1517$, de 18 de junho de 1973.

\title{
História da formação do professor primário no munícipio de Dourados
}

Em Dourados, município do sul de Mato Grosso, a primeira escola que se incumbiu da formação do professor primário foi criada no final da década de 1950, mais precisamente em 1959. Ela foi instalada no Instituto Educacional de Dourados e funcionava no prédio da Escola Confessional Franciscana Patronato de Menores. Mancini, Oliveira e Silva (2007, p. 127) relatam:

\footnotetext{
3 O PABAEE (Programa de Assistência Brasileiro-Americana ao Ensino Elementar) ficou conhecido por contribuir para consolidar, no campo educacional brasileiro nos anos de 1960, a perspectiva tecnicista na análise das questões educacionais. Ao todo, portanto, quase 90 professoras mato-grossenses iniciaram, em 1963, cursos de especialização promovidos pelo "Programa de Recuperação e Aperfeiçoamento do Magistério" do governo Goulart (PINHO, 1964).
} 
Em 1959, as irmãs franciscanas iniciaram um Curso Normal no Instituto Educacional que funcionava no mesmo prédio do Patronato de Menores Santo Antônio. A fundadora do Curso foi a irmã Clara Thomas, diretora da Escola de 1960 a 1961. O curso contava com o Normal Regional (Primeiro Grau) e o Normal Colegial (Segundo Grau). O primeiro começou a funcionar com 08 alunas e o segundo com 06 alunas. A Escola Normal Instituto Educacional de Dourados oferece a partir de 1964 o Curso de Formação de Professores Primários.

A referida instituição era uma escola privada com diretrizes cristãs, isto é, confessional de origem católica, que não atendia a todos os segmentos da sociedade, mas voltava-se para uma clientela constituída pelas elites e classes médias de Dourados e região.

Outro momento importante para a formação de professores no município de Dourados foi a abertura da Escola Normal no Colégio Osvaldo Cruz, na década de 1960. As duas escolas de formação de professores primários existentes nos anos de 1960 ainda não eram suficientes para atender à clientela, como atestam alguns depoimentos encontrados em documentos no Centro Regional de Documentação da Universidade Federal da Grande Dourados. Muitos professores tinham que se deslocar para fazer o curso de formação fora da região, o que acabava gerando insatisfações. Isso pode ser constatado em um relato feito no dia 23 de junho de 1966, por meio do Ofício no 31/66, encaminhado para Ana Izabel de Andrade, que no momento ocupava o cargo de diretora das Escolas Reunidas de Batayporã.

\begin{abstract}
Outrossim, quero nesta oportunidade, solicitar da nobre companheira de lutas, que organize um abaixo assinado entre os professores, solicitando do Exmo. Sr. Governador do Estado e Secretário de Educação e Cultura, que o Curso de Férias para os professores, funcione em Dourados por ser mais fácil acesso, quer de Batayporã, como de todos os municípios vizinhos à Dourados.

O cabeçalho deverá ser o seguinte: Os abaixo-assinados, professores desta região, vem por meio deste solicitar a V. Excia. representados pelo professor Miguel Ângelo do Amaral, a criação e respectivo funcionamento em Dourados, o curso de Regente de Classe, nas mesmas bases que vêm funcionando em C. Grande, Aquidauana, Corumbá e outras cidades do mesmo Estado, visto ser Região muito grande e ter muita dificuldade o professor em se deslocar para outra cidade. Dourados para nós se torna mais perto e de melhor acesso (DOURADOS, 1966, p.1).
\end{abstract}

Relatos como esse da diretora Ana Izabel de Andrade, das Escolas Reunidas de Batayporã, também foram registrados em outros documentos encontrados no Centro Regional de Documentação da Universidade Federal da Grande Dourados. O documento protocolado no dia 10 de abril de 1966, na Diretoria Regional de Ensino de Dourados, localizada nesse centro, fornece informações a respeito do problema e solicita, junto a Secretaria de Educação e Cultura de Mato Grosso, a contratação de uma professora primária para ocupar o cargo de outra professora “[...] que se encontra em Cuiabá (Coxipó da Ponte), fazendo o curso de Treinamento para professores leigos" (DOURADOS, 1966, p.1).

Outro aspecto que também merece destaque, que refletia diretamente no ensino primário, era a falta de professores nas escolas. O Ofício n ${ }^{\circ} 33 / 66$ de 23 de junho de 1966 da $6^{\circ}$ Delegacia do Ensino Primário-Dourados/Sede solicitava ao então Secretário de Educação e Cultura, Sr. Dr. Wilson Rodrigues, a contratação de professores. 
abandonando a escola. [...] Em Douradina abandonaram suas classes 326 crianças. No Laranja Lima 238 crianças. No Panambí 193 crianças. Na Vila Vargas 115 crianças. No Potreirito 206 crianças. Na Vila Nova 63 crianças. Na Escola Vila 29 crianças. Na Vila Jardim Márcia 45 crianças. Na Escola Rural Mista Ramiro Noronha 26 crianças (DOURADOS, 1966, p.1).

$\mathrm{Na}$ tentativa de dar visibilidade aos dados registrados no Ofício $\mathrm{n}^{\circ} 33 / 66$, cumpre destacar que as crianças que abandonavam as escolas moravam, na maioria, em áreas rurais do município de Dourados. É interessante observar que, na década de 1960, a população das áreas rurais era superior à população das áreas urbanas. Segundo dados da Secretaria de Planejamento do governo de Mato Grosso do Sul, apenas $28 \%$ da população viviam em áreas urbanas, e $72 \%$ residiam nas áreas rurais ${ }^{4}$.

Tais inquietações eram pertinentes, pois, desde a Constituição de 1946, o Artigo 168 legislava que o ensino primário deveria ser obrigatório (ROMANELLI, 1986; FREITAS e BICCAS, 2009). Apesar da obrigatoriedade legal, o que se encontrava no município de Dourados, ainda em fins dos anos de 1960, eram crianças sem escolas, em virtude da falta de professores qualificados.

Uma retomada nas questões referentes à instalação de instituições de ensino de formação de professores faz lembrar que "[...] em 1968, foi instalado aqui o primeiro curso de magistério a nível superior no Centro Universitário de Dourados onde passou a funcionar em 1970 o Curso de Agronomia [...]" (ROSA, 1990, p. 171).

Além disso, no ano de 1970, o município teve a sua primeira escola pública de formação de professores instalada, a Escola Normal de Dourados, anexa ao Centro Educacional "Menodora Fialho de Figueiredo", criada mediante ao Art.42, item III da Constituição Estadual:

Art. $1^{\circ}$-Fica criado uma Escola Estadual de $1^{\circ}$ e $2^{\circ}$ Graus, com sede no Município de Dourados denominado pelo Decreto ${ }^{\circ} 1478$ de 11 de março de 1971 de Centro Educacional "Menodora Fialho de Figueiredo".

Art. $2^{\circ}$-Fica integrada a Escola, a Escola Normal de Dourados criada pelo Decreto $\mathrm{n}^{\circ} 1164$, de 27 de maio de 1970.

Parágrafo Único - As Escolas que trata desse Artigo passarão a denominar-se Escola Estadual de $1^{\circ}$ e $2^{\circ}$ Graus "Menodora Fialho de Figueiredo".

Diante de tais circunstâncias, na década de 1970, houve um crescimento na educação, no município, no que diz respeito à formação de professores primários, motivado pela instalação do primeiro curso de magistério em nível superior no Centro Universitário de Dourados e pela criação da Escola Normal de Dourados, anexa ao Centro Educacional "Menodora Fialho de Figueiredo".

Apesar do crescimento no número de escolas de formação de professores em Dourados e da atuação do Programa de Aperfeiçoamento do Magistério Primário (PAMP), por meio do trabalho desenvolvido pelo Centro de Treinamento de Cuiabá na habilitação de professores leigos do município, nos anos de 1970, o ensino rural primário sofria com a falta de professores habilitados para atuar nas escolas rurais primárias. A esse respeito, um bom

\footnotetext{
${ }^{4}$ Dados da Secretaria de Planejamento do Governo de Mato Grosso de 1973.
} 
exemplo pode ser observado em partes de uma matéria de um jornal do município de Dourados, publicada no ano de 1970, que relatava:

O prefeito Jorge Antônio Salomão, disse que está encontrando dificuldades para a contratação, do professorado de nível primário para a zona rural. [...] não está à prefeitura em condições de contratar professoras para a zona rural, incluindo os distritos em número de onze. Essas afirmações do prefeito Jorge Antônio Salomão, intranquilizou a população rural, que se vê ameaçada de ficar sem escolas para o ano letivo a se iniciar, ainda este mês (JORNAL O PROGRESSO, 1970, p. 8).

Diante de tais circunstâncias, as escolas rurais primárias tinham que contar com a colaboração de entidades assistencialistas para tentar reverter o problema. Entre elas estavam o Serviço Social do Instituto Nacional de Previdência Social (INPS) e a Diocese de Dourados, que colaboravam, para os meninos, com aulas volantes teóricas e práticas sobre técnicas básicas de agricultura e, para as meninas, com aulas de Economia Doméstica, Puericultura e Corte de Costura (JORNAL O PROGRESSO, 1970).

Contudo, a ação dessas duas entidades não resolvia o problema, pois muitos alunos continuavam sem escolas e sem professores, uma vez que as aulas desenvolvidas pelo Serviço Social do Instituto Nacional de Previdência Social (INPS) e pela Diocese de Dourados estavam mais voltadas para o aprendizado de trabalhos a serem executados por homens e mulheres em seu cotidiano, do que propriamente a uma formação baseada nos saberes escolares.

Neste contexto marcado por necessidades da população local, mais especificamente da população rural, foi implantado, na década de 1970, o Curso de Magistério Rural ou "Normal de Férias" no município de Dourados.

\section{O curso de Magistério Rural no município de Dourados: implantação e funcionamento}

No ano de 1970, o Departamento de Pesquisa e Ensino solicitou que todas as Delegacias de Ensino do estado de Mato Grosso apresentassem um levantamento das escolas, com dados reais no que se referia ao número de alunos, professores e escolas de sua extensão. Diante dessa determinação, a Delegacia Regional de Ensino de Dourados fez um levantamento de sua realidade educacional, apresentando, em seu relatório final, sugestões para a melhoria do serviço educacional na região, para a Secretária de Educação e Cultura do Estado.

Entretanto, a busca de solução para esse problema só teve início a partir de 1973. No Ofício $\mathrm{n}^{\circ} 172 / 73$, de 01/08/1973, o então prefeito da cidade de Dourados, João da Camara, solicita ao então Secretário da Educação e Cultura do Mato Grosso, Joaquim Alfredo Soares Vianna, a criação de curso supletivo de ensino de $2^{\circ} \mathrm{Grau}$, de educação geral e formação especial para habilitação de docentes leigos com formação em nível de $1^{\circ}$ Grau e de regentes do ensino primário, em exercício. No referido documento, o prefeito local sugeria que esses cursos fossem ministrados em período de férias, e ainda apontava o fato de algumas medidas terem sido adotadas antes, sem muito sucesso. Dentre elas, a de

[...] levar as normalista para a zona rural, ora oferecendo a melhoria salarial, ora dando-lhes dois contratos. Mais essas medidas não trouxeram resultados satisfatórios. Dificilmente o professor qualificado deixa a cidade por mais de dois 
períodos letivos. O número de normalista na zona rural não atinge a $10 \%$, em nosso município (DOURADOS, 1973, p. 1).

O curso autorizado para funcionamento no município de Dourados, foi o de Curso de Magistério Rural. Esse Curso funcionou nas instalações do prédio do Colégio Oswaldo Cruz, uma instituição de ensino particular instalada no município na década de 1960. Apesar de ter ficado sob a responsabilidade da Prefeitura, o curso contava com as verbas do poder público estadual e apenas com uma ajuda suplementar do município, por meio de uma contribuição financeira da Prefeitura local. Na parceria existente entre Estado e Município para o funcionamento do curso, havia uma divisão das funções, pois, enquanto o Estado era o Gestor, o Município apenas se encarregava de remunerar os docentes contratados.

Embora fosse oferecido para todos os professores leigos que trabalhavam nas escolas primárias no período, o curso não era obrigatório aos docentes, conforme registrou uma exaluna, em seu depoimento.

O curso foi oferecido para todos os professores leigos que estavam trabalhando no momento, mais não foi obrigatório, foram abertas as inscrições e dependia do interesse do professor em fazer ou não. Claro que o interessante era fazer, pois assim passaríamos a ter uma titulação e assim até ganhar mais pelo nosso trabalho (M.T., ex-aluna do Curso, entrevistada em 20/01/11).

As entrevistas enfatizaram, ainda, que os professores leigos rurais que tivessem interesse em fazer o curso também receberiam, da Prefeitura, uma bolsa para estadia em Dourados. Tal condição é confirmada pelo relato de uma ex-aluna.

Este curso visava atender às exigências de formação de professores e era oferecido para os professores do Município e do Estado em convênio com o Governo Federal. Por ele ganhávamos uma bolsa paga em dinheiro e estadia (M. C. S., ex-aluna do Curso, entrevistada em 04/02/11).

O Ofício $\mathrm{n}^{\text {o. }} 1542$, de 11 de março de 1974, ratifica o subsídio da Prefeitura de Dourados aos professores leigos que se tornassem alunos do curso de Magistério Rural.

A contrapartida da Prefeitura Municipal será o pagamento dos vencimentos, correspondentes aos períodos em que o curso for ministrado aos professores municipais, mesmo em período de férias. Também, a Prefeitura Municipal se compromete a prestar toda colaboração para êxito do curso (DOURADOS, 1974, p. 1)

Mesmo que esse curso proporcionasse qualificação aos professores leigos, habilitandoos para o exercício do magistério primário, oferecendo bolsa para estadia e propiciando, ainda, a melhoria nas condições salariais do professorado, nem todos os docentes leigos se interessavam pelo curso.

\section{A Organização curricular do curso de Magistério Rural pelo relatos das ex-alunas e antiga professora}


As entrevistas das três ex-alunas e da antiga professora permitiram compreender que tal curso tinha a mesma organização curricular de um curso de Magistério regular vigente no período. A esse respeito, uma ex-professora relatou em entrevista:

Em relação à organização curricular do Curso de Magistério Rural, o que me lembro, é que o Curso reproduzia as estruturas já aprovadas do Curso de Magistério regular, a diferença ocorria apenas na distribuição de carga horária, que tinha que se adaptarem as etapas do Curso. Então eu me lembro que era por aí as diferenças (A.C., ex-professora do Curso, entrevistada em 05/02/2012).

No período de implantação e vigência do Curso de Magistério Rural em Dourados, era a Lei 5. 692/71, que regulamentava o sistema de ensino no Brasil. No que diz respeito à Habilitação Específica para o Magistério, a referida lei determinava que a organização curricular fosse estruturada

[...] em um núcleo comum de formação geral, obrigatório em âmbito nacional composto de disciplinas da área de comunicação e expressão, estudos sociais e ciências - e uma parte de formação especial" - regulamentada pelo Parecer no 349 de 1972, do Conselho Federal de Educação (CFE), constituída por disciplinas de fundamentos de educação, abrangendo aspectos biológicos, psicológicos, sociológicos, históricos e filosóficos da educação, estrutura e funcionamento do ensino de $1^{\circ}$ grau, bem como didática, incluindo prática de ensino [... ] (TANURI, 2000, p.81).

O Curso de Magistério Rural foi organizado para funcionar no período das férias escolares, em dois turnos, com aulas no período diurno e vespertino, para ser realizado em duas etapas, contando com um currículo organizado por disciplinas de formação geral e específica, como ocorria no Curso de Magistério no período. No entanto, a diferença se fazia na carga horária das disciplinas ministradas em um Curso de Magistério Regular e o Curso de Magistério Rural. Desse modo, entre as disciplinas de formação geral estavam: Língua Portuguesa e Literatura, Língua Estrangeira Moderna Inglês, Geografia, História, Organização Social e Política do Brasil, Ciências Físicas e Biológicas, Educação Moral e Cívica, Educação Física, Educação Artística, Programa de Saúde e Ensino Religioso. Já entre as disciplinas de formação específica estavam: Técnicas de Alfabetização, Literatura, Recreação e Jogos, Biologia da Educação, Psicologia da Educação, Sociologia da Educação, História e Filosofia da Educação, Estrutura e Funcionamento de $1^{\text {a }}$ Grau, Estatística Aplicada a Educação, Didática, Práticas de Ensino, Metodologia do Ensino de Comunicação e Expressão, Metodologia do Ensino de Estudos Sociais e Metodologia do Ensino de Ciências e Estágio Supervisionado (A.C., antiga professora do Curso, entrevistada em 05/02/2012).

Entretanto, as entrevistas com ex-alunos e com a ex-professora permitiram compreender que o curso enfatizava, principalmente, o ensino das disciplinas de Alfabetização, de Didática e das disciplinas ligadas às áreas das Metodologias. Fato esse que ficou evidente tanto na entrevista com uma ex-professora e nos depoimentos de ex-alunos. A ex-professora relata:

$\mathrm{Na}$ minha observação, me parecia que a ênfase era nas metodologias, principalmente na metodologia da alfabetização, que era o compromisso, qual era o compromisso da zona rural? Ensinar as crianças ler e a escrever minimamente, porque era só as séries iniciais, era a questão de ler e escrever, calcular. Na minha leitura a ênfase era na didática e nas metodologias (A.C., ex-professora do Curso, entrevistada em 05/02/2012). 
A entrevista de uma ex-aluna confirmou o depoimento da ex-professora.

\begin{abstract}
Lembro-me que falávamos muito nas aulas sobre alfabetização, como ensinar as questões de ler e escrever. Havia uma preocupação maior em relação essa disciplina, e nessas aulas eram as mais interessantes, pois nelas contávamos nossas experiências em sala de aula. Mais pelo o que me lembro o foco maior era na alfabetização das crianças (M.T., ex-aluna do Curso, entrevistada em 20/01/2012).
\end{abstract}

Ao que tudo indica, pode-se dizer que essa ênfase no ensino das disciplinas de Alfabetização, Didática e das Metodologias, no ensino primário, se justifica, pois as atividades de ler, escrever e calcular eram prioridades no processo de ensino-aprendizagem das crianças nas séries iniciais da escolarização. Por outro lado, os docentes leigos que atuavam no ensino primário rural não tinham o menor conhecimento sobre o processo de alfabetização de crianças. Eles desconheciam as metodologias de ensino das disciplinas da escola primária e nunca haviam estudado Didática, uma vez que os mais preparados possuíam, no máximo, o diploma de $1^{\circ}$ grau completo, em nível ginasial.

Ainda é importante registrar que o Curso de Magistério Rural não favorecia a leitura de muitos textos e nem mesmo um aprofundamento dos textos lidos, pois havia muito pouco tempo para as discussões teóricas. A esse respeito, uma ex-aluna revela:

O Curso de Magistério Rural era limitado, não havia tempo de discussões de teoria, a gente lia os textos e respondia as questões predeterminadas de acordo com o nosso entendimento. Era um curso a distância com prestações de contas presenciais (M. A. C., ex-aluna do Curso, entrevistada em 10/02/11).

Esse depoimento deixa evidente que o curso, organizado para se realizar somente no período de férias, acabava exigindo dos alunos uma participação ativa no estudo dos conteúdos das disciplinas que compunham o currículo, uma vez que, durante as aulas, não havia espaço para discussões teóricas e nem mesmo discussões dos textos. O curso também se fazia na forma de ensino à distância, pois, durante as aulas, muitas vezes, aconteciam algumas prestações de contas presenciais, conforme demonstrou o depoimento.

\title{
CONSIDERAÇÕES FINAIS
}

Podemos assim considerar que embora o Curso de Magistério Rural apresentasse a mesma organização curricular de um curso de Magistério regular vigente nos anos de 1970, no município de Dourados, e oferecesse aos professores uma formação de caráter geral e específico, prescrita pelas determinações da Lei de Diretrizes e Bases da Educação Nacional, a Lei $n^{\circ} 5.692 / 71$, com uma organização curricular composta por um núcleo comum e uma parte diversificada, o que se pode verificar em seu funcionamento foi a ênfase dada, sobretudo, às disciplinas de Alfabetização, Didática e das áreas das Metodologias, em uma estrutura organizada com um tempo de duração para ocorrer somente no período de férias escolares dos docentes.

Contudo, pode-se dizer que a instalação e o funcionamento do Curso de Magistério Rural exerceu um importante papel na formação profissional de uma determinada parcela de 
professores leigos rurais primários do município de Dourados, no Sul de Mato Grosso, na década de 1970.

\section{REFERÊNCIAS}

ALBERTI, Verena. Manual de História Oral. Rio de Janeiro: FGV Editora, 2005.

AUGUSTO, Maria Helena. Professor Leigo. Disponível em:〈https://www.gestrado.net.br/pdf/340.pdf>._Acesso em: 10 jan. 2018.

ÁVILA, Virgínia Pereira da Silva de. História do ensino primário rural em São Paulo e Santa Catarina (1921-1952): uma abordagem comparada. 2013. 238 f. Tese (Doutorado em Educação Escolar) - Universidade Estadual Paulista "Julio de Mesquita Filho", Faculdade de Ciências e Letras de Araraquara, 2013.

ÁVILA, Virgínia Pereira da Silva de. Educação Rural em Perspectiva Histórica. Disponível em: 〈http:// http://pensaraeducacaoemrevista.com.br/edicao-atual/>, Ano 4,v. 4, n. 2, p.1-21, Mar-Jul. 2018. Acesso em: 01 de out.2018.

BASTOS, Maria Helena Camara. Prefácio: A educação rural e a formação dos professores. In: WERLE, Flávia Obino Corrêa (org.). Educação Rural: práticas civilizatórias e institucionalização da formação de professores. São Leopoldo: Oikos; Brasília: Líber Livro, 2010.

BECK, Kátia Maria Kunntz. Vivências e memórias: a cultura da Escola Rural Mista Municipal Santo Antônio em Tangará da Serra-MT (1965-1983). 159 f. Dissertação (Mestrado em Educação) - Universidade Federal de Mato Grosso, Cuiabá, 2015.

BITTAR, Marisa. Dos campos grandes à capital dos ipês. Campo Grande: Editora Alvorada, 2004.

CARVALHO, Marta Maria Chagas de. Por uma História Cultural dos Saberes Pedagógicos. In: Sousa, Cynthia Pereira de. et al. Práticas Educativas, Culturas Escolares, Profissão Docente. São Paulo: Escrituras, 1998, p.31-40.

CASTRO, Thalita Pavani Vargas de. Do direito à da infância rural no município de Cuiabá MT (1937 - 1945): Dos quintais aos bancos escolares. 151 f. :il. color. :30 cm. Dissertação (Mestrado em Educação) - Universidade Federal de Mato Grosso, Cuiabá, 2018. 
CAVALCANTE, Aline Do Nascimento. Imprensa e Educação: O Ensino Primário Rural Nas Páginas De Jornais Do Município De Dourados -Mt (1948-1974). 111 f. Dissertação (Mestrado em Educação). Universidade Federal da Grande Dourados. Dourados-MS, 2016.

CHARTIER, Roger. A História Cultural. Lisboa: Difel, 1990.

EBENRITTER, Ana Lucia Borges Pereira. Da escola na casa à Escola Municipal Fazenda Miya do Distrito do Guassú - MT (1965 - 1977). 124f. il: 30 cm. Dissertação. (Mestrado em Educação) - Faculdade de Educação. Universidade Federal da Grande Dourados. Dourados MS, 2018.

FEDATTO, Nilce Aparecida da Silva.; RODRIGUES, Almerinda Maria dos Reis Vieira. Os caminhos da escola nova no Estado de MT nas primeiras décadas do século XX: notas sobre a escola normal e o ideário escolanovista. Educação e Fronteiras, v. 1, p. 101-118, 2007.

FERREIRA, Márcia dos Santos. O Centro de Treinamento do Magistério de Cuiabá e a profissionalização docente em Mato Grosso. Revista de Educação Pública. Cuiabá: UFMT, v.19. n. 30, p.145-161, jan./abr., 2010.

FREITAS, Marcos Cezar de.; BICCAS, Maurilane de Souza. História social da educação no Brasil (1926-1996). São Paulo: Cortez, 2009.

GOODSON, Ivor. Currículo: teoria e história. Petrópolis: Vozes, 2001.

IRALA, Clóvis. Educação Rural Em Dourados: A Escola Geraldino Neves Correa (19421982). 117 f. (Mestrado em Educação) - Faculdade de Educação, Universidade Federal da Grande Dourados, Dourados, 2014.

YOUNG, Michael. O Currículo do Futuro da "Nova Sociologia da Educação" a uma Teoria Crítica do Aprendizado. Campina: Papirus, 2000.

MANCINI, Ana Paula; OLIVEIRA, Magda Sarat; SILVA, Paula Nudimila de Oliveira: História e Memória: normalistas do Instituto Educacional de Dourados 1940-1979. Educação e Fronteiras, Dourados: UFGD, v. 1, n. 1, p. 119-132, jan./jul. 2007

MARCILIO, Humberto. História do ensino em Mato Grosso. Cuiabá: Secretaria de Educação, Cultura e Saúde, 1963. 
PAES, Ademilson Batista. A escola primária rural em Mato Grosso no período republicano (1889 - 1942). 268 f. Tese (Doutorado em Educação) - Faculdade de Ciências e Letras, Universidade Estadual Paulista, Campus de Araraquara, 2011.

PIACENTINE, Ana Paula Fernandes da Silva. História da formação para professores leigos rurais: O curso de Magistério Rural em Dourados, na década de 1970. 103 f. Dissertação (Mestrado em Educação). Universidade Federal da Grande Dourados. Dourados-MS, 2012.

PINHO, Péricles Madureira de. INEP: Súmula das atividades desenvolvidas em 1963. Boletim Informativo CBPE. n. 79, p. 1-9, fev./1964.

QUEIROZ, Maria Isaura Pereira de. Variações sobre a técnica de gravador no registro da informação viva. São Paulo: T. A. Queiroz, 1991.

RODRIGUES, José Ribamar Tôrres. Magistério Leigo Rural do Piauí: Concepções e Práticas. Dissertação (Mestrado em Educação). Pontifícia Universidade Católica. São Paulo, 1985.

RODRIGUEZ, Margarita V.; OLIVEIRA, Regina T. Cestari. Educação em Mato Grosso e Mato Grosso do Sul (1796-2006). FERRO, Olga Maria dos Reis (Org.) História, historiografia, instituições escolares e fontes. Campo Grande: UFMS, 2009.

ROMANELLI, Otaíza de Oliveira. História da Educação no Brasil. Petrópolis:Vozes, 1986.

ROSA, Maria da Glória Sá. Memória da cultura e da educação em Mato Grosso do Sul. Campo Grande: Universidade Federal de Mato Grosso do Sul, 1990.

SILVA, Luciana Vicência do Carmo de Assis e. Na cadência das águas, no ritmo da política: a escola pública rural no município de Poconé-MT (1930-1945). 198 f. :il. color. :30 cm. Dissertação (Mestrado em Educação) - Universidade Federal de Mato Grosso, Cuiabá, 2018a.

SILVA, Silvana Maria da. Memórias da escola rural: Representações da cultura escolar da Escola Rural Mista de Bom Sucesso na memória de ex alunos e uma ex-professora (1937 1952). 2018. 88 f. :il. color. :30 cm. Dissertação (Mestrado em Educação) - Universidade Federal de Mato Grosso, Cuiabá, 2018 b.

SILVA, Marineide de Oliveira da. escola rural: trilhar caminhos e transpor barreiras na educação (1927-1945). 109 f. Dissertação (Mestrado em Educação) - Universidade Federal de Mato Grosso, Cuiabá, 2012. 
TANURI, Leonor Maria. História da formação de professores. Revista Brasileira de Educação. Campinas, n.14, p.61-88, mai./jun./ago.,2000.

WEREBE, Maria José Garcia. Grandezas e misérias do ensino brasileiro. São Paulo. Difusão Européia do Livro, 1963.

\section{FONTES}

A. C. Entrevista de antiga professora do Curso de Magistério Rural do município de Dourados concedida a Ana Paula Fernandes da Silva Piacentine, em fevereiro de 2011. Gravação registrada em gravador de voz digital.

M. C. S. Entrevista de ex-aluna do Curso de Magistério Rural do município de Dourados concedida a Ana Paula Fernandes da Silva Piacentine, em fevereiro de 2011. Gravação registrada em gravador de voz digital.

M.A. C. Entrevista de ex-aluna do Curso de Magistério Rural do município de Dourados concedida a Ana Paula Fernandes da Silva Piacentine, em fevereiro de 2011. Gravação registrada em gravador de voz digital.

M.T. Entrevista de ex-aluna do Curso de Magistério Rural do município de Dourados concedida a Ana Paula Fernandes da Silva Piacentine, em janeiro de 2011. Gravação registrada em gravador de voz digital.

DOURADOS, Jornal o Progresso, 1970 - 1971.

DOURADOS, Ofício n. 31 de 23 de junho de 1966.

DOURADOS, Ofício n. 33 de 23 de junho de 1966.

DOURADOS, Ofício n. 172 de 01 de agosto de 1973.

DOURADOS, Ofício n. 1542 de 11 de março de 1974

MATO GROSSO. Constituição Estadual. Cuiabá. 1970. Centro de Documentação Regional da Universidade Federal da Grande Dourados. 
MATO GROSSO. Mensagem apresentada à Assembléia Legislativa pelo Presidente Manoel Murtinho. Livro 27. Cuiabá, 1907. Arquivo Público de Mato Grosso/Centro de Documentação Regional da Universidade Federal da Grande Dourados.

MATO GROSSO. Mensagem apresentada à Assembléia Legislativa pelo Governador Pedro Celestino Corrêa de Mello. Imprensa Oficial. Cuiabá, 04 de julho de 1911. Arquivo Público de Mato Grosso/Centro de Documentação Regional da Universidade Federal da Grande Dourados.

MATO GROSSO. Governo do Estado. Decreto-Lei n. 287, de 26 de março de 1947. Diário Oficial, Cuiabá, 31 de março de 1947, ANO LVI. Arquivo Histórico de Mato Grosso/ Centro de Documentação Regional da Universidade Federal da Grande Dourados.

MATO GROSSO. Governo do Estado. Decreto-Lei $n^{o .}$ 834, de 31 de janeiro de 1947. Diário Oficial, Cuiabá, 4 de fevereiro de 1947, ANO LVI, p. 9867. Arquivo Histórico de Mato Grosso/ Centro de Documentação Regional da Universidade Federal da Grande Dourados.

MATO GROSSO. Mensagem, apresentada à Assembléia Legislativa pelo Governador do Estado de Mato-Grosso Fernando Corrêa da Costa por ocasião do inicio da Legislatura de 1952. Imprensa Oficial. Cuiabá, 1952. Arquivo Público de Mato Grosso Centro de Documentação Regional da Universidade Federal da Grande Dourados.

Recebido em: 27/07/2017

Aceito em: 20/02/2018 